\title{
Serum Concentrations of Trace Elements in Patients with Crohn's Disease Receiving Enteral Nutrition
}

\author{
Tomoko Johtatsu $^{1}$, Akira Andoh ${ }^{2}$, Mika Kurihara ${ }^{1}$, Hiromi Iwakawa ${ }^{1}$, Tomoyuki Tsujikawa ${ }^{2}$, \\ Atsunori Kashiwagi ${ }^{1}$, Yoshihide Fujiyama ${ }^{2}$, and Masaya Sasaki ${ }^{1}$ * \\ ${ }^{1}$ Division of Clinical Nutrition, Shiga University of Medical Scienece, Seta-Tsukinowa, Otsu 520-2192, Japan \\ ${ }^{2}$ Department of Medicine, Shiga University of Medical Scienece, Seta-Tsukinowa, Otsu 520-2192, Japan
}

Received 13 March, 2007; Accepted 23 April, 2007

\begin{abstract}
Summary We investigated the trace element status in Crohn's disease (CD) patients receiving enteral nutrition, and evaluated the effects of trace element-rich supplementation. Thirty-one patients with CD were enrolled in this study. All patients were placed on an enteral nutrition regimen with Elental ${ }^{\circledR}$ (Ajinomoto pharmaceutical. Ltd., Tokyo, Japan). Serum selenium, zinc and copper concentrations were determined by atomic absorption spectroscopy. Serum selenoprotein $P$ levels were determined by an ELISA system. Average serum levels of albumin, selenium, zinc and copper were $4.1 \pm 0.4 \mathrm{~g} / \mathrm{dl}, 11.2 \pm 2.8 \mu \mathrm{g} / \mathrm{dl}, \quad 71.0 \pm 14.8 \mu \mathrm{g} / \mathrm{dl}$, and $112.0 \pm 25.6 \mu \mathrm{g} / \mathrm{dl}$, respectively. In 9 patients of $31 \mathrm{CD}$ patients, serum albumin levels were lower than the lower limit of the normal range. Serum selenium, zinc and copper levels were lower than lower limits in 12 patients, 9 patients and 1 patient, respectively. Serum selenium levels significantly correlated with both serum selenoprotein $P$ levels and glutathione peroxidase activity. Supplementation of selenium $(100 \mu \mathrm{g} / \mathrm{day})$ and $\mathrm{zinc}(10 \mathrm{mg} / \mathrm{day})$ for 2 months significantly improved the trace element status in CD patients. In conclusion, serum selenium and zinc levels are lower in many CD patients on long-term enteral nutrition. In these patients, supplementation of selenium and zinc was effective in improving the trace element status.
\end{abstract}

Key Words: selenium, zinc, selenoprotein $P$, supplementation

\section{Introduction}

Patients with Crohn's disease (CD) reveal various malnutrition statuses [1-3]. In many studies, deficiencies in trace elements, such as selenium and zinc, have been reported as characteristic features of malnutrition in $\mathrm{CD}$ patients [4-7]. Insufficient oral intake and malabsorption have been considered to be the major causes of trace element deficiencies [1]. Surgical resection of the small intestine

\footnotetext{
*To whom correspondence should be addressed.

Tel: +81-77-548-2217 Fax: +81-77-548-2219

E-mail: sasaki@belle.shiga-med.ac.jp
}

may also reduce the absorption activity of trace elements through decreases in the mucosal absorption area. In addition, since parenteral and enteral nutrition are widely accepted to be effective for inducing and maintaining remission [8-10], CD patients sometimes receive parenteral or enteral nutrition for the management of their disease. Most of the parenteral and enteral formulas commonly used in Japan and the USA do not contain sufficient trace elements $[8,10-12]$, and lead to inadequate supplies of trace elements. In particular, long-term treatment with parentaral or enteral nutrition may induce high-risk trace element deficiencies in $\mathrm{CD}$ patients.

In this study, we investigated the trace element status in $\mathrm{CD}$ patients, and evaluated the effects of trace element-rich 
supplementation.

\section{Subjects and Methods}

\section{Patients}

Thirty-one patients with CD (9 women and 22 men, median age 31 years old) receiving home enteral nutrition were enrolled in this study. All patients were managed in the Division of Gastroenterology at the Hospital of the Shiga University of Medical Science. The ethics committee of the Shiga University of Medical Science approved this study. All patients had the diagnosis of CD established by radiological, histological, and clinical criteria.

All patients had low disease activities [Crohn's disease activity index $(\mathrm{CDAI})<150$ [13]], and these patients were regarded as inactive phase. All patients were placed on an enteral nutrition regimen with Elental $^{\circledR}$ (Ajinomoto pharmaceutical. Ltd., Tokyo, Japan). The daily caloric intake from the enteral nutrition was $1,093 \pm 239$ (mean \pm SD) kcal for over 1 year. The Elental ${ }^{\circledR}$ formula contains a very small amount of selenium and zinc.

A selenium and zinc-rich supplement $\left(\mathrm{V}-\mathrm{Accel}^{\circledR}\right.$, Nutri Co., Tokyo, japan) was used. The daily dosage of V-Acccel ${ }^{\circledR}$ contained $100 \mu \mathrm{g}$ selenium and $10 \mathrm{mg}$ zinc.

Blood was sampled with the patients' informed consent, immediately separated to serum by centrifugation, and kept at $-80^{\circ} \mathrm{C}$ until use.

\section{Analytical methods}

Serum selenium and zinc concentrations were determined by atomic absorption spectroscopy. Other laboratory data were measured by routine methods at the Hospital of the Shiga University of Medical Science. Serum selenoprotein P levels were determined by a previously described ELISA system [6]. Glutathione peroxidase (GPx) activity was determined by a method described by Lowrence et al. [14].

\section{Statistical analysis}

Differences between groups were analyzed with the Kruskal-Wallis test. A $p$ value $<0.05$ was considered to be statistically significant. Correlations were investigated with Spearman rank correlation test.

\section{Result}

Serum levels of albumin, selenium, zinc and copper were determined in $31 \mathrm{CD}$ patients receiving eneteral nutrition. In our hospital, normal ranges of serum levels of albumin, selenium, zinc and copper ranged from 4.0 to $5.2 \mathrm{~g} / \mathrm{dl}$, from 10.6 to $17.4 \mu \mathrm{g} / \mathrm{dl}$, from 64 to $111 \mu \mathrm{g} / \mathrm{dl}$, and from 70 to $132 \mu \mathrm{g} /$ dl, respectively. As shown in Fig. 1, average levels of albumin, selenium, zinc and copper were $4.1 \pm 0.4 \mathrm{~g} / \mathrm{dl}, 11.2 \pm 2.8 \mu \mathrm{g} /$ $\mathrm{dl}, 71.0 \pm 14.8 \mu \mathrm{g} / \mathrm{dl}$, and $112.0 \pm 25.6 \mu \mathrm{g} / \mathrm{dl}$, respectively. In
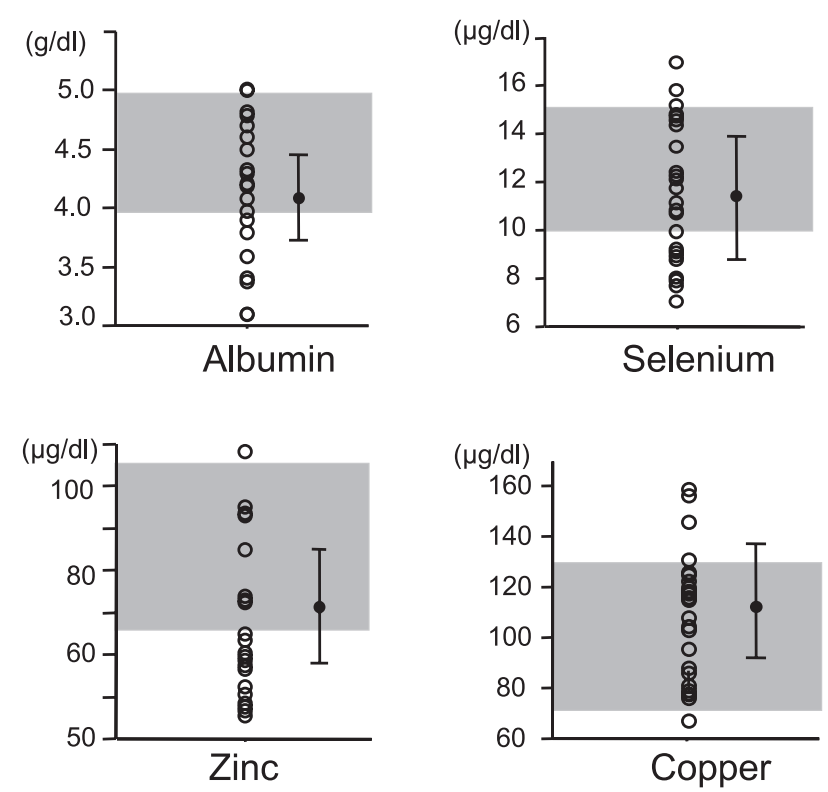

Fig. 1. Serum albumin, selenium, zinc and copper levels in patients with Crohn's disease receiving enteral nutrition for over one year. Dark areas indicate normal ranges. Bars indicate the mean $\pm \mathrm{SD}$.

9 of the $31 \mathrm{CD}$ analyzed patients, serum albumin levels were lower than the lower limit of the normal range. Similarly, serum selenium, zinc and copper levels were lower than the lower limits in 12 patients, 9 patients and 1 patient, respectively.

Selenium is incorporated into proteins via the seleniumcontaining amino acids selenocysteine and selenomethionine. A selenoprotein is a selenocystein-containing protein, and GPX and selenoprotein $\mathrm{P}$ are representative serum selenoproteins. To clarify the significance of serum selenium levels, we assessed the relationship between serum selenium and selenoprotein $\mathrm{P}$ levels and the relationship between serum selenium levels and GPx activity. As shown in Fig. 2, a significant correlation was found between serum selenium and selenoprotein P levels and between serum selenium and GPx activity, respectively. However, there are no significant correlations between serum albumin levels and these factors (serum selenium, selenoprotein P and GPx activity).

In 8 patients whose serum selenium levels were under the lower limit of normal range, we evaluated the effects of selenium- and zinc-rich supplementation. In these patients, no significant correlation between serum trace element levels and albumin levels was observed. Patients orally received selenium-and zinc-rich supplement, and after 2 months changes in serum selenium and zinc levels were determined. The daily dosage of the supplement contained $100 \mu \mathrm{g}$ of selenium and $10 \mathrm{mg}$ of zinc. As shown in Fig. 3, administration of the selenium- and zinc-rich supplement significantly increased serum selenium, zinc levels and GPX activitiy. However, due to a lack of copper in the supplement, 
(A)
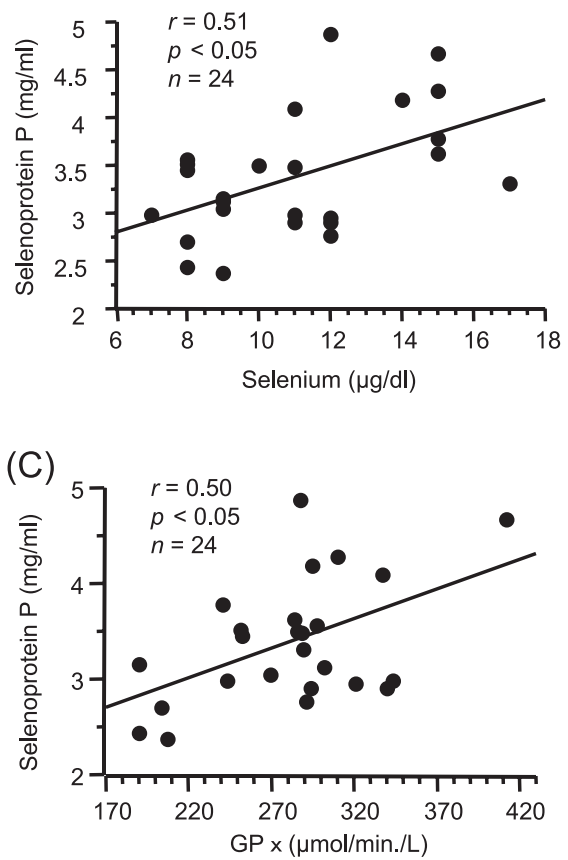

(B)

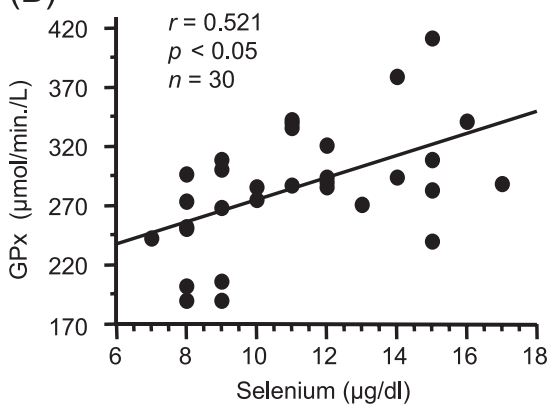

Fig. 2. Correlations among serum selenium levels, selenoprotein P and GPx levels. (A) Correlations between selenium levels and selenoprotein P levels. (B) Correlation between selenium levels and GPx activity. (C) Correlations between GPx activity and selenoprotein P levels.
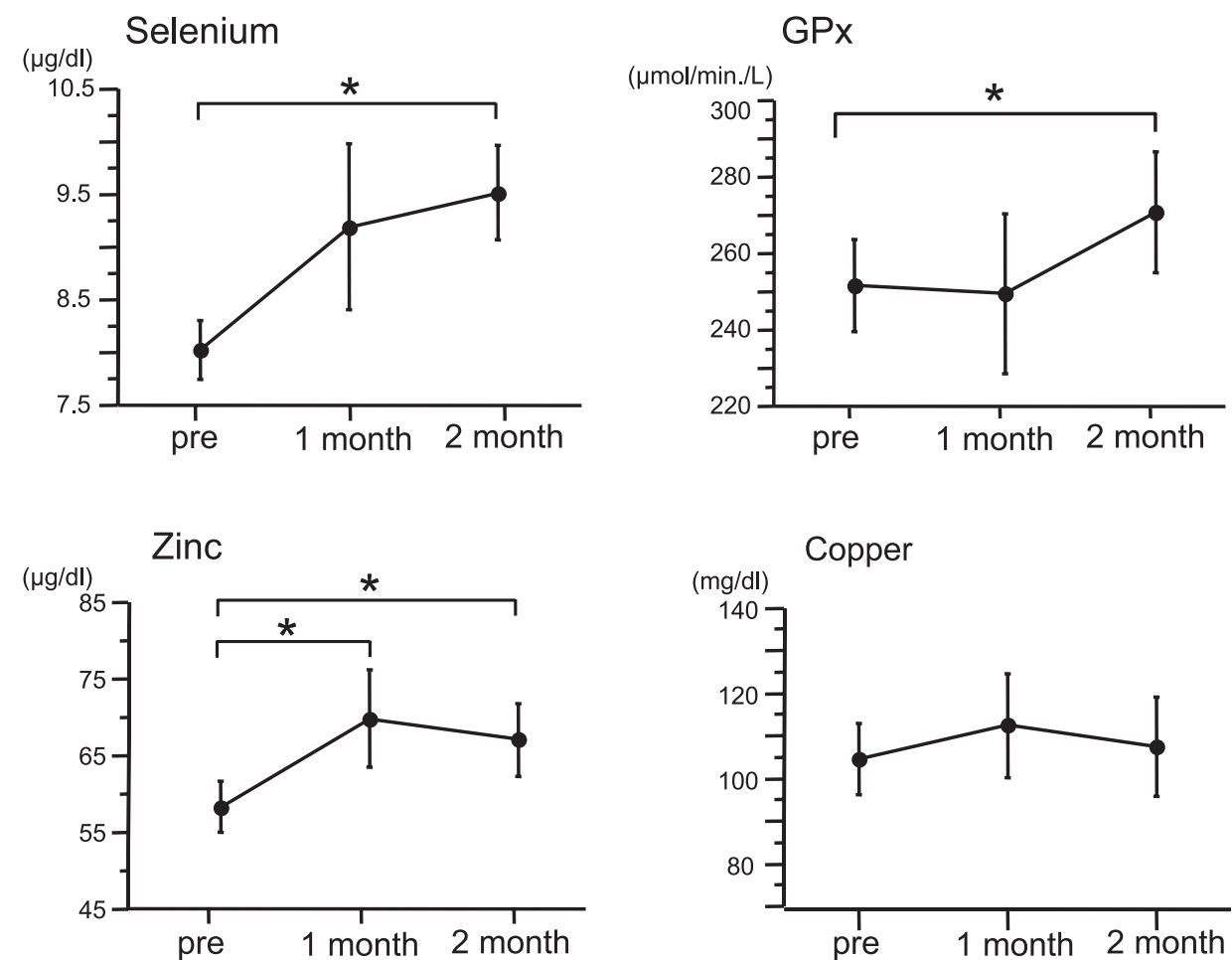

Fig. 3. Effects of selenium- and zinc-rich supplementation. Each data point indicates the mean $\pm \operatorname{SD}(n=8) .{ }^{*} p<0.05$. 
copper levels were not affected. Serum albumin levels did not change after supplementation.

\section{Discussion}

Deficiencies in trace elements, such as selenium and zinc, have been reported in various clinical studies as an indication of malnutrition in CD patients [4, 7, 8, 15-17]. Selenium is an essential trace element that is a component of GPx, a scavenger of hydroperoxides [18]. A selenium deficiency causes a decrease in GPx function, thereby resulting in oxidative damage to many organs. In humans severe selenium deficiencies have been linked to the development of Keshan disease, a dilated congestive cardiomyopathy that primarily occurs in children living in China [19]. Zinc is present in over 80 metalloenzymes that are involved in all the major human metabolic pathways in humans. Zinc is necessary for cell proliferation and has an important role in the maintenance of cellular immunity $[16,17]$. An acute zinc deficiency leads to the development of acrodermatitis, alopecia, diarrhea and depression, and chronic zinc deficiencies cause growth retardation, anorexia, immune disturbance and skin lesions [16].

In this study, we observed that serum selenium and zinc levels were lower than the lower limits of normal ranges in 38.7 and $29.0 \%$ of CD patients receiving enteral nutrition for a long time period, respectively. In contrast, copper levels were normal in most of the patients. The findings reported herein are consistent with previous reports $[4,15]$.

Trace element deficiencies in CD patients may result from a variety of processes, including reduced dietary intake, impaired mucosal absorption, increased excretion, and hypoalbuminemia [16]. In these processes, two factors may be important: mucosal malabsorption of trace elements and trace element-deficient nutrition. Nishida et al. previously demonstrated that zinc absorption is reduced even in histologically normal jejunal mucosa [20]. A similar mechanism might be applied for selenium absorption. CD patients sometimes receive parenteral nutrition or enteral nutrition for the management of malnutrition [8-10], and selenium and zinc deficiencies occurs in $\mathrm{CD}$ patients who are nourished alone by parentaral or enteral nutrition for a long period of time $[7,8,10,11]$. Trace element deficiencies are associated with inadequate supplies of trace elements by parentaral and enteral nutrition, since most of the parentaral or enteral formulas do not contain sufficient trace elements $[8,10-12]$. Thus, with the use of parenteral and enteral nutrition in CD patients, much attention should be paid to avoid the development of trace element deficiencies. All of our cases were inactive phase of disease, and major factor contributed to low serum selenium and zinc levels might be inadequate supplies of trace elements by enteral nutrition.

Selenoprotein $\mathrm{P}$ contains 10 selenocystein residues per molecule, and is a plasma protein that carries more than $50 \%$ of the plasma selenium $[6,21,22]$. Selenoprotein $\mathrm{P}$ is an important selenium supplier from the liver to the peripheral tissues [22]. More importantly, selenoprotein P is a free radical scavenger for peroxynitrite and phospholipidhydroperoxide [6]. Like GPx, selenoprotein P is an important serum antioxidant factor, and protects cells from oxidative stress. In this study, serum selenium levels were associated with serum selenoprotein P levels and GPx activity, suggesting that the antioxidant status might be reduced in CD patients receiving enteral nutrition for a long period of time. Since it has been suggested that active oxygen species play an important role in the pathogenesis of inflammatory bowel diseases (IBD) $[6,18]$, improvements in the selenium status might be relevant to reduce disease activity.

Based on findings of lower serum trace element levels, we orally administered selenium and zinc-rich supplement in 8 patients. As initially expected, selenium and zinc supplementation significantly improved selenium and zincstatus in these patients. Although no consensus has been reached on the dosage of trace elements to be administered, the recommended therapeutic dose of selenium ranges from $100 \mu \mathrm{g}$ to $400 \mu \mathrm{g} /$ day $[23,24]$. Zinc requirements range from $2 \mathrm{mg}$ to $12 \mathrm{mg} /$ day [16]. Our supplementation formula consisted of $100 \mu \mathrm{g} /$ day of selenium and $10 \mathrm{mg} /$ day of zinc, and was sufficient for $\mathrm{CD}$ patients receiving enteral nutrition. Improvements in the trace element status suggest that trace element supplementation should be performed in $\mathrm{CD}$ patients receiving long-term entral nutrition. No patients showed symptoms of lower trace elements, and this might be du to that clinical symptoms appear as a result of longer-term and much severer reduction of serum trace element levels. However, the antioxidant status in these patients might be recovered through improvement in selenium deficiency.

In conclusion, selenium and zinc deficiencies should be considered in $\mathrm{CD}$ patients receiving enteral nutrition for a long period of time. In these patients, selenium $(100 \mu \mathrm{g} / \mathrm{day})$ and zinc $(10 \mathrm{mg} /$ day) supplementation for 2 months was effective in improving the trace element status.

\section{Acknowledgment}

Each author equally contributed to manuscript preparation. No disclosure conflict of interest.

\section{Abbreviations}

IBD, inflammatory bowel disease; CD, Crohn's disease; GPx, glutathione peroxidise; CDAI, Crohn's disease activity index. 


\section{References}

[1] Kastin, D.A. and Buchman, A.L.: Malnutrition and gastrointestinal disease. Curr. Opin. Clin. Nutr. Metab. Care., 5, 699-706, 2002.

[2] Naveh, Y.: Malnutrition and growth retardation in children and adolescents with Crohn's disease. Harefuah, 136, 726$729,1999$.

[3] Jeejeebhoy, K.N.: The many faces of malnutrition in Crohn disease. Am. J. Clin. Nutr., 67, 819-820, 1998.

[4] Ringstad, J., Kildebo, S., and Thomassen, Y.: Serum selenium, copper, and zinc concentrations in Crohn's disease and ulcerative colitis. Scand. J. Gastroenterol., 28, 605-608, 1993.

[5] El-Tawil, A.M.: Zinc deficiency in men with Crohn's disease may contribute to poor sperm function and male infertility. Andrologia, 35, 337-341, 2003.

[6] Andoh, A., Hirashima, M., Maeda, H., Hata, K., Inatomi, O., Tsujikawa, T., Sasaki, M., Takahashi, K., and Fujiyama, Y.: Serum selenoprotein-P levels in patients with inflammatory bowel disease. Nutrition, 21, 574-579, 2005.

[7] Kuroki, F., Matsumoto, T., and Iida, M.: Selenium is depleted in Crohn's disease on enteral nutrition. Dig. Dis., 21, 266270, 2003.

[8] Hiwatashi, N.: Enteral nutrition for Crohn's disease in Japan. Dis. Colon. Rectum, 40, S48-53, 1997.

[9] Matsueda, K., Shoda, R., Takazoe, M., Hiwatashi, N., Bamba, T., Kobayashi, K., Saito, T., Terano, A., and Yao, T.: Therapeutic efficacy of cyclic home elemental enteral alimentation in Crohn's disease: Japanese cooperative Crohn's disease study. J. Gastroenterol., 30 Suppl 8, 91-94, 1995.

[10] Tsujikawa, T., Andoh, A., and Fujiyama, Y.: Enteral and parenteral nutrition therapy for Crohn's disease. Curr. Pharm. Des., 9, 323-332, 2003.

[11] Martin, R.F., Young, V.R., and Janghorbani, M.: Selenium content of enteral formulas. JPEN. J. Parenter. Enteral. Nutr., 10, 213-215, 1986.

[12] Zabel, N.L., Harland, J., Gormican, A.T., and Ganther, H.E.: Selenium content of commercial formula diets. Am. J. Clin. Nutr., 31, 850-858, 1978.

[13] Harve, R.F. and Bradshaw, M.J.: Measuring Crohn's disease activity. Lancet, 1, 1134-1135, 1980.
[14] Lowrence, R.A.S.R., Schwartz, G.L., and Hoelstra, W.G.: Glutathione peroxidase activity in rat lens and other tissues in relation to dietary selenium intake. Exp. Eye Res., 18, 563569, 1974.

[15] Fernandez-Banares, F., Mingorance, M.D., Esteve, M., Cabre, E., Lachica, M., Abad-Lacruz, A., Gil, A., Humbert, P., Boix, J., and Gassull, M.A.: Serum zinc, copper, and selenium levels in inflammatory bowel disease: effect of total enteral nutrition on trace element status. Am. J. Gastroenterol., 85, 1584-1589, 1990.

[16] Matsui, T.: Zinc deficiency in Crohn's disease. J. Gastroenterol., 33, 924-925, 1998.

[17] McClain, C., Soutor, C., and Zieve, L.: Zinc deficiency: a complication of Crohn's disease. Gastroenterology, 78, 272$279,1980$.

[18] Hatanaka, N., Nakaden, H., Yamamoto, Y., Matsuo, S., Fujikawa, T., and Matsusue, S.: Selenium kinetics and changes in glutathione peroxidase activities in patients receiving long-term parenteral nutrition and effects of supplementation with selenite. Nutrition, 16, 22-26, 2000.

[19] Yang, F.Y., Lin, Z.H., Li, S.G., Guo, B.Q., and Yin, Y.S.: Keshan disease - an endemic mitochondrial cardiomyopathy in China. J. Trace Elem. Electrolytes Health. Dis., 2, 157$163,1988$.

[20] Nishida, K., Yao, T., and Tsuzuki, S.: Mechanism of zinc deficiency in Crohn's disease. Jpn. J. Gastroenterol., 82, 424-433, 1985.

[21] Hill, K.E., Lloyd, R.S., Yang, J.G., Read, R., and Burk, R.F.: The cDNA for rat selenoprotein P contains 10 TGA codons in the open reading frame. J. Biol. Chem., 266, 1005010053, 1991.

[22] Schomburg, L., Schweizer, U., Holtmann, B., Flohe, L., Sendtner, M., and Kohrle, J.: Gene disruption discloses role of selenoprotein $\mathrm{P}$ in selenium delivery to target tissues. Biochem. J., 370, 397-402, 2003.

[23] van Rij, A.M., McKenzie J.M., Thomson, C.D., and Robinson, M.F.: Selenium supplementation in total parenteral nutrition. JPEN J. Parenter. Enteral. Nutr., 5, 120-124, 1981.

[24] Ishida, T., Himeno, K., Torigoe, Y., Inoue, M., Wakisaka, O., Tabuki, T., Ono, H., Honda, K., Mori, T., Seike, M., Yoshimatsu, H., and Sakata, T.: Selenium deficiency in a patient with Crohn's disease receiving long-term total parenteral nutrition. Intern. Med., 42, 154-157, 2003. 